\title{
Behavioural and clinical predictors for Loiasis
}

\author{
Johannes Mischlinger ${ }^{1,2,3,4}$, \\ Luzia Veletzky1,2,4, \\ Gildas B Tazemda-Kuitsouc ${ }^{5}$, \\ Paul Pitzinger ${ }^{1,2}$, Pierre B \\ Matsegui2,3,5, Markus Gmeiner ${ }^{2,3}$, \\ Heimo Lagler ${ }^{1}$, Tamirat Gebru ${ }^{2,3}$, \\ Jana Held ${ }^{2,3}$, \\ Benjamin Mordmüller, ${ }^{2,3}$, \\ Michael Ramharter 1,2,3,4 \\ ${ }^{1}$ Department of Medicine I, Division of \\ Infectious Diseases and Tropical Medicine, \\ Medical University of Vienna, Vienna, Austria \\ ${ }^{2}$ Centre de Recherches Médicales de \\ Lambaréné, Lambaréné, Gabon \\ ${ }^{3}$ Institut für Tropenmedizin, Universität \\ Tübingen, and German Center for Infection \\ Research, partner site Tübingen, Tübingen, \\ Germany \\ ${ }^{4}$ Bernhard Nocht Hospital for Tropical \\ Diseases, Bernhard Nocht Institute for \\ Tropical Medicine and University Medical \\ Center Hamburg-Eppendorf, Hamburg, \\ Germany \\ ${ }^{5}$ Centre de Recherches Médicales de la \\ Ngounié, Fougamou, Gabon
}

\begin{abstract}
Background Loiasis is a vector-borne disease in Central and West Africa. While there is still uncertainty to what extent loiasis is responsible for population morbidity, individuals having both loiasis and onchocerciasis have a high risk of fatal encephalopathy when treatment (ie, ivermectin) for onchocerciasis is given. Therefore it is current policy that communities of high loiasis-burden are excluded from mass drug administration programmes of ivermectin. To address this treatment gap we present diagnostic scores, based on clinical and behavioural predictors that may help to rapidly identify sub-groups with loiasis within high-burden communities.
\end{abstract}

Methods A cross-sectional survey was performed in the province of la Ngounie, Gabon between December 2015 and Februrary 2016 and 947 participants of all ages were recruited. Clinical parameters and behavioural exposure factors were ascertained by questionnaire-based interviews. Parasitological analysis of blood samples was performed for L. loa detection. Diagnostic scores consisting of clinical and behavioural factors were modelled to predict loiasis in sub-groups residing in endemic regions.

Results Increasing sylvan exposure was identified as important risk factor for loiasis with adjusted odds ratios of 5.1 (95\% confidence interval CI 2.6-9.9) for occasional forest exposure, 11.1 (95\% CI 5.4-22.6) for frequent forest exposure and 25.7 (95\% CI 12.5-52.9) for intensive forest exposure. Individuals with loiasis were 7.7 (95\% CI 5.4-11.0) times more likely to report recurrent pruritus than those without loiasis. Reporting of regular daily exposure to the deep rain forest and recurrent pruritus was 9-fold (positive likelihood ratio 9.18; 95\% CI: 6.39-13.18) more prevalent in individuals with loiasis than in controls. Concordantly, the absence of regular weekly forest exposure was associated with extremely low disease-likelihood (negative likelihood ratio 0.09; 95\% CI 0.05-0.16).

Conclusions These composite scores may serve as a simple tool to rapidly identify both those most and those least at risk of disease and may simplify loiasis control activities as well as screening procedures for studies on loiasis. Further, they may aid policy-makers to tailor the delivery of ivermectin mass drug administration for onchocerciasis control programmes more effectively and safely in regions of high loiasis-burden.

\section{Correspondence to:}

Assoc. Prof. Michael Ramharter, MD, DTM\&H

Medical University of Vienna

Währinger Gürtel 18-20

1090 Vienna

Austria

michael.ramharter@meduniwien.ac.at
Loiasis is a filarial disease which is endemic in Central- and West Africa $[1,2]$. It is transmitted via the Chrysops fly, which relies on damp woody vegetation as habitat. Pathognomonic symptoms are Calabar swelling, a non-pitting edema occurring mostly over boney prominences, and notion of a worm migrating through the eye [3-6]. Calabar swelling was shown to occur more frequently in Caucasians and history of eye worm more often in Africans $[4,7]$. In addition, loiasis causes a variety of non-specific symptoms, the most commonly reported one being recurrent pruritus $[4,8,9]$.

L. loa has attracted considerable attention in the context of onchocerciasis control programmes [2]. Onchocerciasis is controlled by repeated mass drug administration of ivermectin. Ivermectin may however lead to an unacceptable risk for encephalopathy, when administered to patients with high microfilarial counts of L. loa [10]. The identification of communities with 
high prevalence of L. loa microfilariaemia was therefore vital to exclude those communities from mass drug administration programmes. Over the past decade this epidemiological identification of populations has been performed by the "Rapid assessment procedure for Loa loa" (RAPLOA) - an assessment relying on the history of eye worm migration $[11,12]$. However, RAPLOA has not been designed and evaluated for the identification of loiasis in individual patients.

The diagnosis of loiasis in individual patients is based on the detection of the adult worm, microfilariae, or serological tests [2]. Microfilariae can be detected by light microscopy of peripheral blood with peak microfilaraemia occurring around noon. However, a significant proportion of patients may suffer from occult loiasis with an absence of microfilaremia and cross detection of antibodies limits the usefulness of serology $[13,14]$. Loiasis is therefore difficult to diagnose in endemic settings. The identification of subgroups most at risk for the disease is therefore of high importance to adequately allocate limited resources for further diagnostic assessments in the health care sector.

To address these diagnostic challenges and to identify high-risk sub-groups, this study aimed to determine predictors for loiasis. Based on the systematic evaluation of predictors diagnostic composite scores were created $[15,16]$.

\section{METHODS}

\section{Participants}

This cross-sectional survey was conducted in rural central Gabon in the province of la Ngounié, a region covered by tropical rain forest [17]. Between December 2015 and February 2016 study teams visited rural villages surrounding the administrative capital Fougamou and actively recruited villagers in this survey. Community leaders were informed one week prior to the screening activities and the entire community was invited to participate.

\section{Questionnaire for behavioural and occupational predictors}

Questionnaire-based interviews were performed to obtain occupational status and the degree of forest exposure. Forest exposure was defined as "none" (no significant activities in the forest), "occasional" (twice per week exposure to forest), "frequent" (daily activities in the forest) and "intensive" (daily exposure to deep tropical rain forest). Either "occasional", "frequent" or "intensive" exposure was defined as "regular weekly" exposure. These definitions assumed temporal regularity of exposures and were recorded as indicated by the participant.

\section{Parasitological and clinical definitions}

Blood was sampled between 10:00 and 15:00 and thick blood smears of $10 \mu \mathrm{L}$ were performed and stained with 4\% Giemsa solution for 60 minutes for parasitological analysis with light microscopy. Loiasis was defined as either the presence of L. loa microfilariae in a blood sample or a positive history of eyeworm as defined by RAPLOA assessment - a case definition of history of eyeworm endorsed by the World Health Organisation $[11,12]$. Calabar swelling was not part of the case definition, because it was shown previously that its inclusion can lead to a high false positivity rate [11]. When asked for "eyeworm", concepts of the local languages were used ("DOBBA" in Shira language). Pruritus was chosen as non-specific symptom and was assessed for all participants $[4,8,9]$. Pruritus was defined as any recurrent itch reported by a patient or caregiver of a child, for which there was no apparent alternative aetiology in medical history and clinical examination. To further assess the distribution of Calabar swelling among different behavioural exposures, history of Calabar swelling was assessed in a sub-sample of the study population. It was defined as the presence of a uni-lateral, recurring, non-pitting edema that stays for multiple days.

\section{Ethics statement}

The study was conducted according to the ethical principles stated in the Declaration of Helsinki, the applicable guidelines for ICH-GCP, and the applicable laws and regulations of Gabon. Individual written informed consent was obtained from all adult participants. For minors, a parent or legal guardian was asked to sign informed consent on their behalf and from minors above the age of 12 additionally assent was obtained. The study was part of two epidemiological studies on malaria that were approved by the independent ethics committee of the Centre de Recherches Médicales de Lambaréné [18]. 


\section{Statistical considerations}

STATA 13 (StataCorp, College Station, Texas, TX, USA) was used for statistical analyses. Stata-software packages were downloaded to allow the creation of proportional Venn diagrammes and the computation of diagnostic test performance characteristics $[19,20]$. Performance characteristics were determined for composite exposures on the basis of the presence/absence of pruritus and various degrees of forest exposure. $\chi^{2}$-tests were used for proportions, likelihood ratio tests to obtain p-values for logistic regression models and the test of homgeneity was used to discriminate between confounders and effect modifiers. Cochran-Armitage trend test was used for trend analysis for proportions across an ordinal variable [21]. Post-test probabilities were calculated as described by Kent et al. [22]. The STATA 'direct standardization' command for survey data was used to estimate the proportion of Calabar swelling in the overall study population. Information on distribution of Calabar swelling among the age-strata in the sub-population was extrapolated to the age-structure of the overall study population. A significance level of two-sided $\alpha<0.05$ was considered as statistically significant.

\section{RESULTS}

In total 947 participants were recruited with a median age of 22 years (interquartile range (IQR) 8-51) and a male/female ratio of 0.84 (Table 1). 289 out of 947 (30.5\%) had loiasis according to our case definition and positivity for RAPLOA was the most frequent loiasis-defining characteristic $(65.1 \%$; 188/289) (Table 2). Prevalence of pruritus was 32.3\% (306/947) in the overall study population and $67.2 \%$ (636/947) reported being regularly engaged in activities that involved exposure to the forest at least twice weekly. The sub-study assessing Calabar swelling recruited 213 participants (median age 16; IQR 7 - 40, male/female ratio of 0.90). 60/213 (28.2\%) had loiasis.

Table 1. Baseline characteristics

\begin{tabular}{|c|c|c|c|}
\hline & ТотАL соновт $(\mathbb{N}=947)$ & LoiAsis $(n=289)$ & Population of Calabar swelling sub-study (n = 213) \\
\hline Characteristics & No. (column \%) & No. (row \%) & No. (column \%) \\
\hline \multicolumn{4}{|l|}{ Age (years): } \\
\hline Median (IQR) & $22(8-51)$ & $51(32-65)$ & $16(7-40)$ \\
\hline Below 6 & $160(16.9 \%)$ & $2(1.3 \%)$ & $44(20.6 \%)$ \\
\hline 6 to 17 & $272(28.7 \%)$ & $26(9.6 \%)$ & $65(30.5 \%)$ \\
\hline 18 to 34 & $147(15.5 \%)$ & $52(35.4 \%)$ & $37(17.4 \%)$ \\
\hline 35 to 49 & $120(12.7 \%)$ & $60(50 \%)$ & $27(12.7 \%)$ \\
\hline 50 to 64 & $113(11.9 \%)$ & $65(57.5 \%)$ & $13(6.1 \%)$ \\
\hline 65 or older & $135(14.3 \%)$ & $84(62.2 \%)$ & $27(12.7 \%)$ \\
\hline \multicolumn{4}{|l|}{ Sex: } \\
\hline Male & $434(45.8 \%)$ & $124(28.6 \%)$ & $101(47.4 \%)$ \\
\hline \multicolumn{4}{|c|}{ Exposure to forest: } \\
\hline None & $311(32.8 \%)$ & $12(3.9 \%)$ & $67(31.5 \%)$ \\
\hline Occasional & $237(25 \%)$ & $42(17.7 \%)$ & $76(35.7 \%)$ \\
\hline Frequent & $173(18.3 \%)$ & $82(47.4 \%)$ & $42(19.7 \%)$ \\
\hline Intensive & $226(23.9 \%)$ & $153(67.7 \%)$ & $28(13.1 \%)$ \\
\hline \multicolumn{4}{|l|}{ RAPLOA: } \\
\hline Positive & $245(25.9 \%)$ & $245(100 \%)$ & $46(21.6 \%)$ \\
\hline \multicolumn{4}{|l|}{ Microfilaraemia: } \\
\hline Positive & $101(10.7 \%)$ & $101(100 \%)$ & $24(11.3 \%)$ \\
\hline \multicolumn{4}{|c|}{ RAPLOA or microfilaraemia: } \\
\hline Positive & $289(30.5 \%)$ & $289(100 \%)$ & $60(28.2 \%)$ \\
\hline \multicolumn{4}{|l|}{ Pruritus: } \\
\hline Positive & $306(32.3 \%)$ & $206(67.3 \%)$ & $42(19.7 \%)$ \\
\hline \multicolumn{4}{|c|}{ History of Calabar swelling: } \\
\hline Positive & $13.3 \%(7.1-23.5)^{*}$ & $10(62.5 \%) \dagger$ & $16(7.5 \%)$ \\
\hline
\end{tabular}

RAPLOA - rapid assessment procedure for Loa loa

*Percentage (95\% CI) of history of Calabar swelling was estimated through direct standardization of results from the sub-study population ( $\mathrm{n}=213)$ using the age-structure of the whole population $(\mathrm{N}=947)$.

†alculated only for people with loiasis $(n=16)$ of sub-study population $(n=213)$. 
Table 2. Cross-tabulation of loiasis-defining characteristics* TotaL NI = 947 RAPLOA + (N, ROW \%) RAPLOA - (N, ROW \%)

Microfilaraemia $+\quad 57(56.4 \%) \quad 44(43.6 \%)$

Microfilaraemia - $188(22.2 \%) \quad 658(77.8 \%)$

RAPLOA - rapid assessment procedure for Loa loa $* \chi^{2}$ test $(P<0.001)$.
The prevalence of loiasis rises as the exposure to forest becomes more intensive $(P<0.001)$ (Table 3$)$. Crude odds ratios $(\mathrm{ORs})$ demonstrate that the odds for loiasis rises by the factor of 5.4 (95\% CI 2.7-10.7) for occasional exposure, 22.5 (95\% CI 10.448.3) for frequent exposure and 52.2 (95\% CI 21.7-125.7) for intensive exposure when compared to no forest exposure. Adjusting for sex and age reduces the overall association, however remaining highly statistically significant $(P<0.001)$.

Table 3. Predictors for loiasis

\begin{tabular}{|c|c|c|c|}
\hline Predictors FOR LOIASIS & LoIASIs $(\mathbb{N}=\mathbf{2 8 9})$ & Crude OR (95\% CI) & Adjusted OR (95\% CI) \\
\hline \multicolumn{4}{|l|}{ Age (years): } \\
\hline Below 6 & $2(1.3 \%) *$ & 1 & 1 \\
\hline 6 to 17 & $26(9.6 \%) *$ & $8.3(1.9-36.4)$ & $7.9(1.8-34.3) \dagger$ \\
\hline 18 to 34 & $52(35.4 \%)^{*}$ & $43.2(8.7-215.8)$ & $36.1(7.2-180.6) \dagger$ \\
\hline 35 to 49 & $60(50 \%)^{*}$ & $79(13.4-464.8)$ & $57.9(8.6-391.7) \dagger$ \\
\hline 50 to 64 & $65(57.5 \%) *$ & $107(16.2-708.6)$ & $69.8(7.4-662.3) \dagger$ \\
\hline 65 or older & $84(62.2 \%)^{*}$ & $130.1(18.8-901.6)$ & $73.9(5.0-1099.9) \dagger$ \\
\hline \multicolumn{4}{|l|}{ Sex: } \\
\hline Female & $165(32.2 \%) \ddagger$ & 1 & 1 \\
\hline Male & $124(28.6 \%) \ddagger$ & $0.84(0.6-1.1)$ & $1(0.7-1.4) \S$ \\
\hline \multicolumn{4}{|l|}{ Exposure to forest: } \\
\hline None & $12(3.9 \%) *$ & 1 & 1 \\
\hline Occasional & $42(17.7 \%)^{*}$ & $5.4(2.7-10.7)$ & $5.1(2.6-9.9) \|$ \\
\hline Frequent & $82(47.4 \%)^{*}$ & $22.5(10.4-48.3)$ & $11.1(5.4-22.6) \|$ \\
\hline Intensive & $153(67.7 \%)^{*}$ & $52.2(21.7-125.7)$ & $25.7(12.5-52.9) \|$ \\
\hline \multicolumn{4}{|l|}{ Pruritus: } \\
\hline No & $83(12.9 \%)^{*}$ & 1 & 1 \\
\hline Yes & $206(67.3 \%)^{*}$ & $13.8(9.3-20.6)$ & $7.7(5.4-11.0) \|$ \\
\hline
\end{tabular}

Table 4. Frequency of history of Calabar swelling in various strata

\begin{tabular}{lc}
$\begin{array}{l}\text { Characteristics } \\
\text { Age (years): }\end{array}$ & \multicolumn{1}{c}{ Higtory of Calabar swelung $(\mathbf{W}=\mathbf{1 6})^{*}$} \\
\hline Below 6 & $1(1.5 \%) \dagger$ \\
\hline 6 to 17 & $6(16.2 \%) \dagger$ \\
\hline 18 to 34 & $4(14.8 \%) \dagger$ \\
\hline 35 to 49 & $2(15.4 \%) \dagger$ \\
\hline 50 to 64 & $3(11.1 \%) \dagger$ \\
\hline 65 or older & $6(5.4 \%) \dagger$ \\
\hline Sex: & $10(9.9 \%) \dagger$ \\
\hline Female & $4(6 \%) \S$ \\
\hline Male & $2(2.6 \%) \S$ \\
\hline Exposure to forest: & $3(7.1 \%) \S$ \\
\hline None & $7(25 \%) \S$ \\
\hline Occasional & \\
\hline Frequent & $4(2.3 \%) \|$ \\
\hline Prtensive & $12(28.6 \%) \|$ \\
\hline No
\end{tabular}

*Total of 213 participants included in the Calabar swelling sub-study. $\dagger \chi^{2}$ test $(P=0.012)$; Cochran-Armitage test for trend $(P=0.001)$.

$\neq \chi^{2}$ test $(P=0.21)$.

$\S \chi^{2}$ test $(P=0.002)$; Cochran-Armitage test for trend $(P=0.006)$.

$\| \chi^{2}$ test $(P<0.001)$.
Pruritus was more common in persons with loiasis (206/306; 67.3\%; $P<0.001$ ) with a crude odds ratio of 13.8 (95\% CI 9.320.6). Adjustment for age and sex reduces the odds ratio but it remains highly statistically significant (OR7.7, 95\% CI 5.4-11.0); $P<0.001)$.

In the sub-study population 16 participants $(7.5 \%)$ reported a recent episode of Calabar swelling (Table 4). Among participants with loiasis 10 individuals $(10 / 60,16.7 \%)$ reported a history of Calabar swelling $(P=0.002)$. Among all 16 participants with history of Calabar swelling 12 (75\%) reported 'regular weekly forest exposure', 2/12 (16.6\%) reported occasional, 3/12 (35.0\%) frequent and 7/12 (58.3\%) intensive exposure. Twelve out of 16 (75.0\%) reported pruritus. History of Calabar swelling was not common in pediatric participants but occurred in a frequency of $11.1 \%$ to $16.2 \%$ in various age groups of adult participants $(P=0.012)$. History of Calabar swelling was more common in male individuals ( $9.9 \%$ vs $5.4 \%$ in women), but the association was not significant $(P=0.21)$. The Cochran-Armitage test for trend was highly significant between history of Calabar swelling and the degree of sylvan exposures $(P=0.006)$ and age groups $(P=0.001)$.

$70.9 \%$ of people with occasional forest exposure and over 90\% with daily exposure reported subsistence activities as reason for forest exposure (Table 5). Sylvan subsistence activities increased 


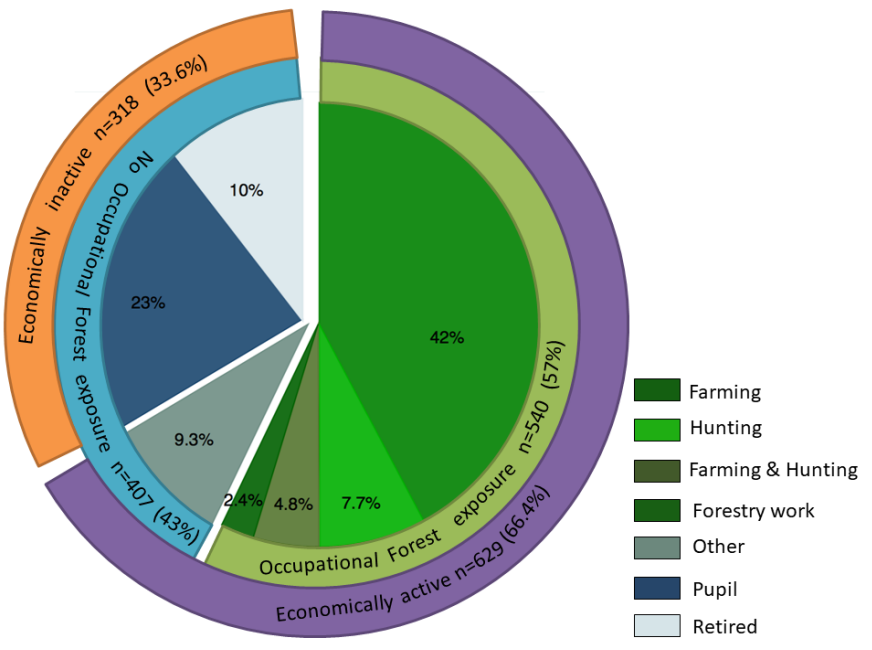

Figure 1. Pie chart, demonstrating occupational status of participants.

Table 5. Factors associated with subsistence activities in the forest

\begin{tabular}{|c|c|}
\hline Characteristics & $\begin{array}{l}\text { SUbSISTENCE ACTIVIIIES IN THE FOREST } \\
\text { ( } \mathbb{N}=947)\end{array}$ \\
\hline \multicolumn{2}{|l|}{ Age (years): } \\
\hline Below 6 & $17(10.6 \%) *$ \\
\hline 6 to 17 & $108(39.7 \%)^{*}$ \\
\hline 18 to 34 & $96(65.3 \%)^{*}$ \\
\hline 35 to 49 & $103(85.8 \%)^{*}$ \\
\hline 50 to 64 & $97(85.8 \%) *$ \\
\hline 65 or older & $119(88.2 \%)^{*}$ \\
\hline \multicolumn{2}{|l|}{ Sex: } \\
\hline Female & $292(56.9 \%) \dagger$ \\
\hline Male & $248(57.1 \%) \dagger$ \\
\hline \multicolumn{2}{|c|}{ Exposure to forest: } \\
\hline None & $0 *$ \\
\hline Occasional & $168(70.9 \%) *$ \\
\hline Frequent & $163(94.2 \%) *$ \\
\hline Intensive & $209(92.5 \%) *$ \\
\hline \multicolumn{2}{|l|}{ Loiasis: } \\
\hline Negative & $293(44.5 \%)^{*}$ \\
\hline Positive & $247(85.5 \%)^{*}$ \\
\hline
\end{tabular}

with age ranging from $10.6 \%(17 / 160)$ in participants below 6 years of age to 88.2\% (119/135) in people aged 65 or older. Cochran-Armitage tests for trend were highly significant $(P<0.001)$. There were no differences between the two sexes $(P=0.99)$.

Various occupational activities of participants were investigated (Figure 1). Among all 947 participants 400 (42.2\%) engaged in farming activity, 73 (7.7\%) in hunting, 45 (4.8\%) in farming and hunting, 23 (2.4\%) in forestry work and 88 (9.3\%) had other professions that did not involve exposure to the forest. 219/947 (23.1\%) pupils and 99/947 (10.5\%) retired people reported not to be engaged in any economic or occupational activity.

A series of proportional Venn diagrammes show the overlap between loiasis, pruritus and various degrees of sylvan exposures (Figure 2).

"Regular weekly forest exposure" had the highest sensitvity with $95.8 \%$ and the most favourable negative likelihood ratio which was 0.09 (95\% CI 0.05-0.16). The combined presence of "pruritus" and "intensive forest exposure" had the highest positive likelihood ratio, which was 9.18 (95\% CI 6.39-13.18) and an overall area under the receiver operating characteristic (ROC) curve of 0.8 (95\% CI 0.76-0.83) (Table 6 and Table 7)

\section{DISCUSSION}

Loiasis is a neglected tropical disease that occurs in forested regions of Central and West Africa. This study shows that varying degrees of sylvan exposures are important risk factors for loiasis, a finding supported by the transmission cycle with the Chrysops fly serving as the vector and having its habitat in the high-canopied parts of the tropical rain forest $[1,2]$.

The intensity of forest exposure of rural populations in this region is associated with age, sex and socio-economic status. Women engage more often in subsistence agriculture and men more frequently in hunting activities farther in the deep forest. In general, socioeconomic status and wealth are correlated inversely with forest
Figure 2. Series of proportional Venn diagrammes showing the overlap of loiasis, pruritus and various degrees of sylvan exposures. From left to right: "No exposure" - no significant activities in the forest; "occasional" - twice per week; "frequent" - daily activities in the forest; "intensive" - daily activities in the deep tropical rain forest.

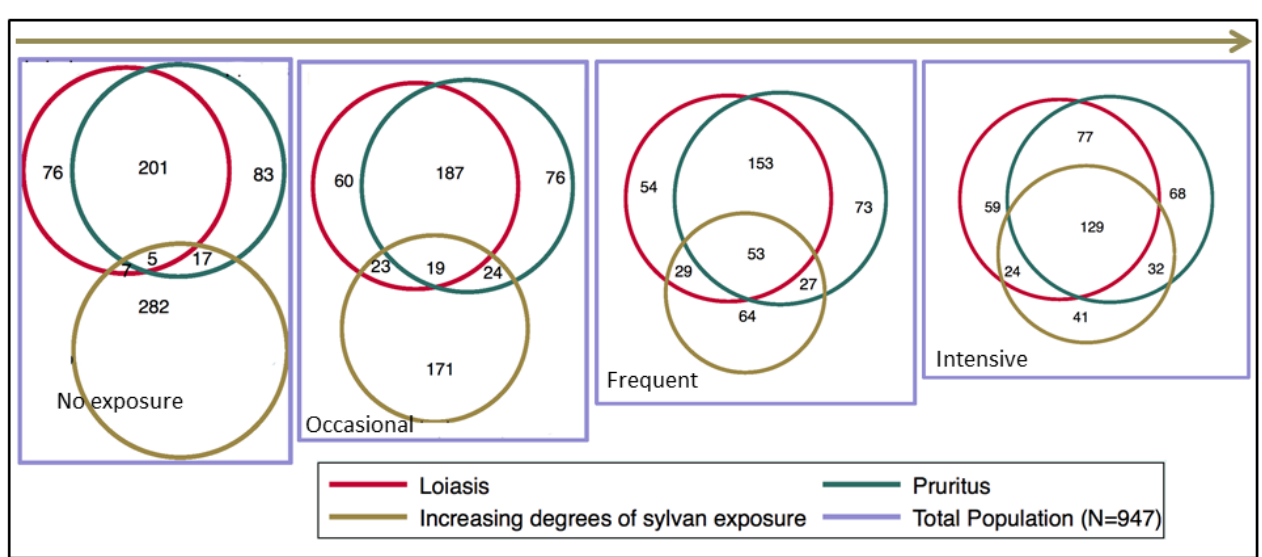


Table 6. Performance characteristics of different composite exposures computed from presence of pruritus and sylvan exposure (part 1)

\begin{tabular}{|c|c|c|c|c|}
\hline Composite Exposure & SenSITIVITY $(\%, 95 \%$ CI) & SPECIFICITY $(\%, 95 \%$ CI) & PPV $(\%, 95 \%$ CI) & NPV $(\%, 95 \%$ CI) \\
\hline Regular weekly forest exposure $\dagger$ & $95.8 \%(92.9-97.8)$ & $45.4 \%(41.6-49.3)$ & $43.6 \%(39.7-47.5)$ & $96.1 \%(93.4-98.0)$ \\
\hline Occasional forest exposure & $14.5 \%(10.7-19.1)$ & $70 \%(66.7-73.8)$ & $17.7 \%(13.1-23.2)$ & $65.2 \%(61.6-68.7)$ \\
\hline Frequent forest exposure & $28.4 \%(23.2-33.9)$ & $86.2 \%(83.3-88.7)$ & $47.4 \%(39.8-55.1)$ & $73.3 \%(70.0-76.3)$ \\
\hline Intensive forest exposure & $52.9 \%(47.0-58.8)$ & $88.9 \%(86.3-91.2)$ & $67.7 \%(61.2-73.7)$ & $81.1 \%(78.1-83.9)$ \\
\hline (Frequent or intensive) forest exposure & $81.3 \%(76.3-85.6)$ & $75.1 \%(71.6-78.3)$ & $58.9 \%(53.9-63.8)$ & $90.1 \%(87.3-92.5)$ \\
\hline Pruritus & $71.3 \%(65.7-76.4)$ & $84.8 \%(81.8-87.5)$ & $67.3 \%(61.8-72.5)$ & $87.1 \%(84.2-89.6)$ \\
\hline Pruritus + regular weekly forest exposure & $69.6 \%(63.9-74.8)$ & $87.4 \%(84.6-89.8)$ & $70.8 \%(65.1-76.0)$ & $86.7 \%(83.9-89.2) *$ \\
\hline Pruritus+occasional forest exposure & $6.6 \%(4.0-10.1)$ & $96.4 \%(94.6-97.6)$ & $44.2 \%(29.1-60.1)$ & $70.1 \%(67.0-73.1)$ \\
\hline Pruritus + frequent forest exposure & $18.3 \%(14.0-23.3)$ & $95.9 \%(94.1-97.3)$ & $66.3 \%(54.8-76.4)$ & $72.8 \%(69.7-75.7)$ \\
\hline Pruritus + intensive forest exposure & $44.6 \%(38.8-50.6)$ & $95.1 \%(93.2-96.7)$ & $80.1 \%(73.1-86.0)$ & $79.6 \%(76.7-82.4)$ \\
\hline Pruritus + (frequent or intensive) forest exposure & $63 \%(57.1-68.6)$ & $91 \%(88.6-93.1)$ & $75.5 \%(69.6-80.8)$ & $84.8 \%(82.0-87.4)$ \\
\hline
\end{tabular}

$\mathrm{CI}$ - confidence interval, PPV - positive predictive value, NPV - negative predictive value

*NPV of 97.6\% (95.1 - 99.0) if both pruritus \& regular weekly forest exposure are reported negative.

†"Regular weekly forest exposure" defined as at least twice per week.

Table 7. Performance characteristics of different composite exposures computed from presence of pruritus and sylvan exposure (part 2)*

\begin{tabular}{|c|c|c|c|c|c|}
\hline Composite exposure & $\begin{array}{c}\mathbf{L R}(+) \\
\text { (RATIO, 95\% CI) }\end{array}$ & $\begin{array}{c}\text { LR (-) } \\
\text { (RATIO, 95\% CI) }\end{array}$ & $\begin{array}{l}\text { Area UNDER ROC } \\
\text { CURVE (95\% CI) }\end{array}$ & $\begin{array}{c}\text { Post-IEST P (+) } \\
(\%, 95 \% \text { CI) }\end{array}$ & $\begin{array}{l}\text { PoST-IEST P (-) } \\
(\%, 95 \% \text { CI) }\end{array}$ \\
\hline Regular weekly forest exposure & $1.76(1.63-1.89)$ & $0.09(0.05-0.16)$ & $0.69(0.68-0.72)$ & $43.6 \%(39.7-47.5)$ & $3.9 \%(2.0-6.6)$ \\
\hline Occasional forest exposure & $0.49(0.36-0.66)$ & $1.21(1.13-1.30)$ & $0.41(0.38-0.44)$ & $17.7 \%(13.1-23.2)$ & $34.8 \%(31.3-38.4)$ \\
\hline Frequent forest exposure & $2.05(1.57-2.67)$ & $0.83(0.77-0.90)$ & $0.60(0.56-0.64)$ & $47.4 \%(39.8-55.1)$ & $26.7 \%(23.7-30.0)$ \\
\hline Intensive forest exposure & $4.77(3.75-6.08)$ & $0.53(0.47-0.60)$ & $0.74(0.71-0.78)$ & $67.7 \%(61.2-73.7)$ & $18.9 \%(16.1-21.9)$ \\
\hline (Frequent or intensive) forest exposure & $3.26(2.83-3.77)$ & $0.25(0.19-0.32)$ & $0.75(0.72-0.77)$ & $58.9 \%(53.9-63.8)$ & $9.9 \%(7.5-12.7)$ \\
\hline Pruritus & $4.69(3.86-5.70)$ & $0.34(0.28-0.41)$ & $0.77(0.74-0.81)$ & $67.3 \%(61.8-72.5)$ & $12.9 \%(10.4-15.8)$ \\
\hline Pruritus + regular weekly forest exposure & $5.51(4.45-6.84)$ & $0.35(0.29-0.42) \dagger$ & $0.79(0.76-0.82)$ & $70.8 \%(65.1-76.0)$ & $13.3 \%(10.8-16.1) \dagger$ \\
\hline Pruritus + occasional forest exposure & $1.80(1.00-3.24)$ & $0.97(0.94-1.00)$ & $0.57(0.50-0.65)$ & $44.2 \%(29.1-60.1)$ & $29.9 \%(26.9-33.0)$ \\
\hline Pruritus + frequent forest exposure & $4.47(2.87-6.96)$ & $0.85(0.80-0.90)$ & $0.70(0.64-0.75)$ & $66.3 \%(54.8-76.4)$ & $27.2 \%(24.3-30.3)$ \\
\hline Pruritus + intensive forest exposure & $9.18(6.39-13.18)$ & $0.58(0.52-0.65)$ & $0.80(0.76-0.83)$ & $80.1 \%(73.1-86.0)$ & $20.4 \%(17.6-23.3)$ \\
\hline Pruritus + (frequent or intensive) forest exposure & $7.02(5.42-9.10)$ & $0.41(0.35-0.47)$ & $0.80(0.77-0.83)$ & $75.5 \%(69.6-80.8)$ & $15.2 \%(12.6-18.0)$ \\
\hline
\end{tabular}

LR (+) - likelihood ratio for positive test result; LR (-) - likelihood ratio for negative test result; Post-test p (+) - post-test probability for positive result; Post-test $\mathrm{p}(-)$ - post-test probability for negative result, ROC - receiver operating characteristic curve, $\mathrm{CI}$ - confidence interval

*N.B.: Pre-test probability for loiasis in the study population $=30.5 \%$.

†LR (-) of 0.06 (0.03-0.12) and post-test p (-) of 2.4\% (1-0-4.9) if both pruritus \& regular weekly forest exposure are reported negative.

exposure in this region. Subsistence farming, hunting and fishing in the forest are major sources of nutrition for people without formal employment. This observation is in accordance with a study from Nigeria demonstrating an association between low socioeconomic status and loiasis [23].

Loiasis prevalence increases with age based on the fact that it is contracted through progressive accumulation of infections and that the adult worms may live for up to 20 years in the human host [24]. However, the two youngest participants with loiasis were only 5 years of age and were reportedly taken to the rain forest by parents who engaged in twice weekly subsistence agriculture. Females more frequently had loiasis than males ( $32.2 \%$ vs $28.6 \%$, respectively), but this is due to the higher proportion of elderly females participating in the study. Therefore, if adjusted for age the odds ratio of 1 (1-1.1) demonstrates no sex preference for loiasis.

The analysis of risk factors for loiasis in this study population stresses the importance of forest exposure for transmission. Adjusted odds for loiasis increase by a factor of 5.1 (2.6-9.9) with occasional sylvan exposure, 11.1 (5.4-22.6) with frequent sylvan exposure and by 25.7 (12.5-52.9) with intensive sylvan exposure. This highly significant association demonstrates the importance of forest exposure for successful transmission of $L$. loa and points towards potential means for the interruption of its transmission cycle. Inversely, absence of regular activities in the rain forest is a marked protective factor against loiasis (LR of 0.09). This is consistent with entomological research showing that Chrysops flies do not usually come close to human habitats and rarely bite indoors [25]. Similarly, reports from Nigeria and Cameroon showed an association between loiasis and occupational activity in muddy areas and rainforests $[26,27]$ and an- 
other study from Gabon showed that agricultural activity and hunting were positvely correlated with loiasis [28]. This is consistent with our findings with regards to the fact that the majority of hunters report intensive forest exposure and those who engage in agricultural activity report any kind of regular weekly forest exposure.

Unspecific symptoms attributable to loiasis are not well understood but pruritus is the most commonly cited complaint $[4,8,9]$. A study from the Republic of Congo demonstrated that pruritus occurred in $64.4 \%$ in a population highly endemic for loiasis [8]. Another Congolese study showed that pruritus was reported as at least "frequent" in 50\% (27/50) and 83\% (25/30) by two different cohorts with parasitologically confirmed loiasis [9]. A survey from Eastern Cameroon $(n=4146)$ did not determine the frequency of non-specific pruritus, but showed that among individuals with Calabar swelling pruritus occurred up to $94 \%$ [29]. In this study $(n=213) 75 \%(12 / 16)$ of individuals with history of Calabar swelling reported pruritus, but only $28.6 \%$ (12/42) of those with pruritus also were positive for history of Calabar swelling. Churchill et al. reported a frequency of pruritus of $27 \%$ among African immigrants (14/51) and European expatriates (13/49) who presented at the Hospital of Tropical Diseases in London [4]. Based on this sparse evidence pruritus may be more prevalent in endemic populations than in migrants or travellers and may therefore serve as a clinical predictor for loiasis in Central and West Africa.

The sub-population investigated for Calabar swelling indicated that a proportion of 7.5\% (16/213) reported a recent episode of edema suggestive for loiasis. Interestingly, Calabar swelling occurred in only 10 out of 60 participants $(16.7 \%)$ who met the case definition of loiasis $(P=0.002)$. This rather low proportion of Calabar swelling is consistent with previous reports indicating that this clinical manifestation of loiasis occurs less frequently in persons residing in endemic regions than in travellers $[4,7]$.

\section{Diagnostic scores}

To date, obtaining information on history of eyeworm in its restricted RAPLOA definition is the simplest and most valid method to detect communities of high loiasis burdens [11,12,30]. On individual level highest diagnostic validities, however, may be gained by investigation of multiple, high volume samples of blood, applying concentration techniques and subsequent assessment by microscopy and molecular techniques [2]. This study relied on the assessment of eye worm migration in addition to microscopy of thick smears of $10 \mu \mathrm{l}$ of peripheral blood. It is understood that this diagnostic method may be associated with lower prevalence of microfilaraemia than the above-mentioned methods and therefore constitutes a limitation of the analysis, as potential cases may have wrongly been classified as controls. However, we are confident that these measures are relevant on an epidemiological scale in regions of high L. loa transmission. Previous epidemiological studies from Gabon support these findings reporting concordant disease prevalences of $22 \%$ and $40 \%[28,30]$. A strength of this survey is the representativeness of the study population due to the absence of any relevant exclusion criteria for study-participation.

Based on forest exposure and pruritus a prediction score was calculated to identify those persons most at risk for loiasis in resource-limited settings, where further laboratory-based testing is challenging. First, absence of regular weekly forest exposure was associated with a negative likelihood ratio of 0.09 corresponding to a large, almost conclusive decrease of disease-likelihood. This translates to a post-test probability of $3.9 \%$ for loiasis in a population with a pre-test probability of $30.5 \%$. The combined absence of regular weekly forest exposure and pruritus decreased this already low post-test probability further to $2.4 \%$. Therefore the absence of "regular weekly forest exposure" may help to rule out loiasis in the absence of state-of-the-art diagnostics.

On the opposite the presence of "pruritus" combined with "intensive forest exposure" led to a positive likelihood ratio of 9.18, which constitutes a large and nearly conclusive increase of disease-likelihood. This translates into a post-test probability of $80.1 \%$ for loiasis in this study-population and to potentially even higher post-test probabilities in populations of higher loiasis prevalence [31]. It is of mention that areas under the ROC curve for many composite exposures yielded values indicating almost excellent performance.

Based on this score persons most at risk for loiasis may be readily identified by two simple questions about forest exposure and pruritus on a sub-population level in regions of L. loa endemicity. This may be particularly useful in the setting of onchocerciasis control programmes as well as in clinical research on loiasis [2]. Finally, individual patients may benefit from such a risk-based approach by employing further laboratory based testing to those with highest probability of loiasis. 


\section{CONCLUSION}

Loiasis is a neglected tropical disease that occurs in rural parts of Central and West Africa, where diagnostic tools are often not readily available. This study demonstrates that increasing degrees of sylvan exposure are marked risk factors for loiasis and provides diagnostic composite scores for the estimation of disease-risk. In regions of high L. loa endimicity these scores may be used to rapidly identify groups with highest likelihood for loiasis. High-risk individuals may constitute an epidemiological key group in the infection cycle between the disease vector and the human host and may therefore play a crucial role in the transmission of L. loa. It is this group of individuals which should be targeted for further diagnostic evaluation to start controlling loiasis in endemic regions of Central and West Africa. Further, the present diagnostic scores may aid policy-makers to tailor the delivery of ivermectin mass drug administration for onchocerciasis control programmes more effectively and safely in regions of high L. loa burden.

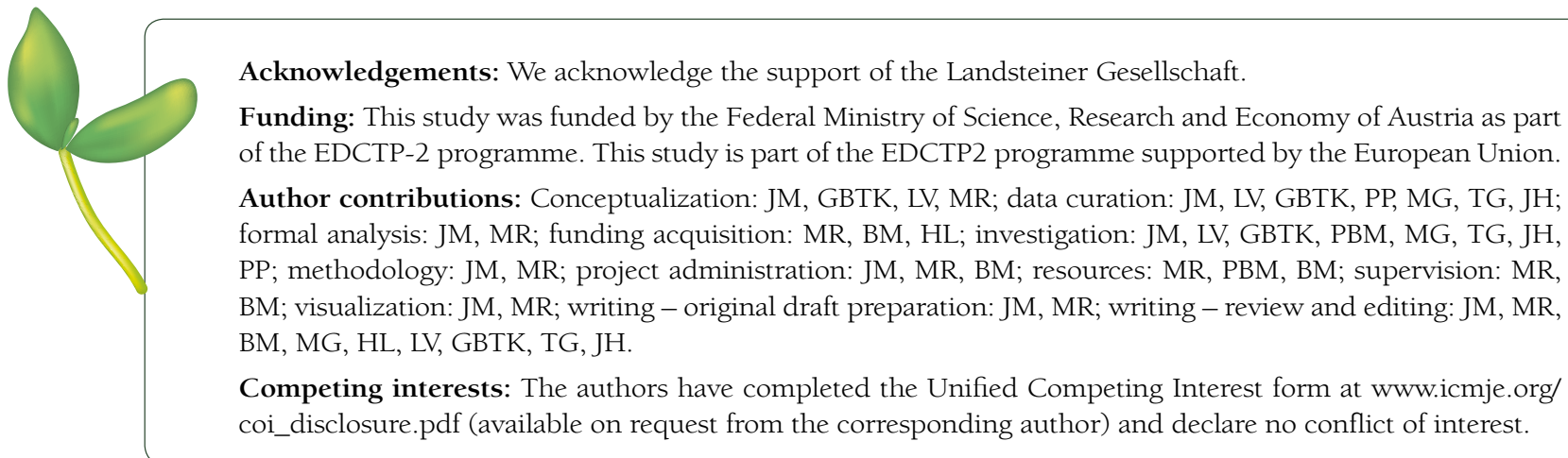

1 Kelly-Hope LA, Bockarie MJ, Molyneux DH. Loa loa ecology in central Africa: role of the Congo River system. PLoS Negl Trop Dis. 2012;6:e1605. Medline:22745838 doi:10.1371/journal.pntd.0001605

2 Metzger WG, Mordmuller B. Loa loa-does it deserve to be neglected? Lancet Infect Dis. 2014;14:353-7. Medline:24332895 doi:10.1016/S1473-3099(13)70263-9

3 Antinori S, Schifanella L, Million M, Galimberti L, Ferraris L, Mandia L, et al. Imported Loa loa filariasis: three cases and a review of cases reported in non-endemic countries in the past 25 years. Int J Infect Dis. 2012;16:e649-62. Medline:22784545 doi:10.1016/j.ijid.2012.05.1023

4 Churchill DR, Morris C, Fakoya A, Wright SG, Davidson RN. Clinical and Laboratory Features of Patients with Loiasis (Loa Ioa filariasis) in the U.K. J Infect. 1996;33:103-9. Medline:8889997 doi:10.1016/S0163-4453(96)93005-4

5 Gantois N, Rapp C, Gautret P, Ficko C, Savini H, Larreche S, et al. Imported loiasis in France: a retrospective analysis of 47 cases. Travel Med Infect Dis. 2013;11:366-73. Medline:24035648 doi:10.1016/j.tmaid.2013.08.005

6 Rakita RM, White AC Jr, Kielhofner MA. Loa loa infection as a cause of migratory angioedema: report of three cases from the Texas Medical Center. Clin Infect Dis. 1993;17:691-4. Medline:8268351 doi:10.1093/clinids/17.4.691

7 Klion AD, Massougbodji A, Sadeler BC, Ottesen EA, Nutman TB. Loiasis in endemic and nonendemic populations: immunologically mediated differences in clinical presentation. J Infect Dis. 1991;163:1318-25. Medline:2037798 doi:10.1093/infdis/163.6.1318

8 Noireau F, Apembet JD, Nzoulani A, Carme B. Clinical manifestations of loiasis in an endemic area in the Congo. Trop Med Parasitol. 1990;41:37-9. Medline:2339244

9 Carme B, Mamboueni JP, Copin N, Noireau F. Clinical and biological study of Loa loa filariasis in Congolese. Am J Trop Med Hyg. 1989;41:331-7. Medline:2679158 doi:10.4269/ajtmh.1989.41.331

10 Hoerauf A, Pfarr K, Mand S, Debrah AY, Specht S. Filariasis in Africa-treatment challenges and prospects. Clin Microbiol Infect. 2011;17:977-85. Medline:21722251 doi:10.1111/j.1469-0691.2011.03586.x

11 Takougang I, Meremikwu M, Wandji S, Yenshu EV, Aripko B, Lamlenn SB, et al. Rapid assessment method for prevalence and intensity of Loa loa infection. Bull World Health Organ. 2002;80:852-8. Medline:12481206

12 World Health Organization. TDR. Guidelines for the rapid assessment of Loa Loa. 2002. Available: http://www.who.int/ tdr/publications/tdr-research-publications/loa-loa/en/. Accessed: 15 June 2016.

13 Pinder M. Loa loa - a neglected filaria. Parasitol Today. 1988;4:279-84. Medline:15463001 doi:10.1016/01694758(88)90019-1

14 Boussinesq M. Loiasis. Ann Trop Med Parasitol. 2006;100:715-31. Medline:17227650 doi:10.1179/136485906X112194

15 Bossuyt PM, Reitsma JB, Bruns DE, Gatsonis CA, Glasziou PP, Irwig L, et al. STARD 2015: an updated list of essential items for reporting diagnostic accuracy studies. Radiology. 2015; 277:826-32. Medline:26509226 doi:10.1148/radiol.2015151516 
16 von Elm E, Altman DG, Egger M, Pocock SJ, Gotzsche PC, Vandenbroucke JP. The Strengthening the Reporting of Observational Studies in Epidemiology (STROBE) statement: guidelines for reporting observational studies. Bull World Health Organ. 2007;85:867-72. Medline:18038077 doi:10.2471/BLT.07.045120

17 Manego RZ, Mombo-Ngoma G, Witte M, Held J, Gmeiner M, Gebru T, et al. Demography, maternal health and the epidemiology of malaria and other major infectious diseases in the rural department Tsamba-Magotsi, Ngounie Province, in central African Gabon. BMC Public Health. 2017;17:130. Medline:28129759 doi:10.1186/s12889-017-4045-x

18 Ramharter M, Adegnika AA, Agnandji ST, Matsiegui PB, Grobusch MP, Winkler S, et al. History and perspectives of medical research at the Albert Schweitzer Hospital in Lambarene, Gabon. Wien Klin Wochenschr. 2007;119:8-12. Medline:17987353 doi:10.1007/s00508-007-0857-5

19 Seed P. DIAGT: Stata module to report summary statistics for diagnostic tests compared to true disease status. 2001. Available: https://ideas.repec.org/c/boc/bocode/s423401.html. Accessed: 10 December 2016.

20 Gong W, Ostermann J. PVENN: Stata module to create proportional Venn diagram. 2011. Available: https://ideas.repec. org/c/boc/bocode/s457368.html. Accessed: 10 December 2016.

21 Royston P. PTREND: Stata module for trend analysis for proportions. 2002. Available: https://econpapers.repec.org/software/bocbocode/s426101.htm. Accessed: 18 November 2017.

22 Kent P, Hancock MJ. Interpretation of dichotomous outcomes: sensitivity, specificity, likelihood ratios, and pre-test and post-test probability. J Physiother. 2016;62(4):231-3. Medline:27637768 doi:10.1016/j.jphys.2016.08.008

23 Ufomadu GO, Nwoke BE, Akoh JI, Sato Y, Ekejindu GO, Uchida A, et al. The occurrence of loiasis, mansonellosis and wuchereriasis in the Jarawa River Valley, central Nigeria. Acta Trop. 1990;48:137-47. Medline:1980569 doi:10.1016/0001706X(90)90053-3

24 Padgett JJ, Jacobsen KH. Loiasis: African eye worm. Trans R Soc Trop Med Hyg. 2008;102:983-9. Medline:18466939 doi:10.1016/j.trstmh.2008.03.022

25 World Health Organization. Vector Control - Methods for Use by Individuals and Communities. 1997. Available at: http:// www.who.int/docstore/water_sanitation_health/vectcontrol/ch06.htm-b6-Horseflies\%20and\%20deerflies\%20\%28tabanids\%29. Accessed: 9 November 2016.

26 Agbolade O, Akinboye D. Detection of microfilariae with counting chamber technique in some Nigerian rural communities. Afr J Biotechnol. 2005;4:367.

27 Wanji S, Tendongfor N, Esum M, Atanga SN, Enyong P. Heterogeneity in the prevalence and intensity of loiasis in five contrasting bioecological zones in Cameroon. Trans R Soc Trop Med Hyg. 2003;97:183-7. Medline:14584374 doi:10.1016/ S0035-9203(03)90114-3

28 Akue JP, Nkoghe D, Padilla C, Moussavou G, Moukana H, Mbou RA, et al. Epidemiology of concomitant infection due to Loa loa and Mansonella perstans in Gabon. PLoS Negl Trop Dis. 2011;5:e1329. Medline:22022623 doi:10.1371/journal.pntd.0001329

29 Takougang I, Meli J, Lamlenn S, Tatah PN, Ntep M. Loiasis-a neglected and under-estimated affliction: endemicity, morbidity and perceptions in eastern Cameroon. Ann Trop Med Parasitol. 2007;101:151-60. Medline:17316501 doi:10.1179/136485907X154511

30 Zouré HG, Wanji S, Noma M, Amazigo UV, Diggle PJ, Tekle AH, et al. The geographic distribution of Loa loa in Africa: results of large-scale implementation of the Rapid Assessment Procedure for Loiasis (RAPLOA). PLoS Negl Trop Dis. 2011;5:e1210. Medline:21738809 doi:10.1371/journal.pntd.0001210

31 Mischlinger J, Schernhammer E. A common trap of diagnostic tests: disease prevalence and positive predictive value (PPV). Wien Klin Wochenschr. 2017;129. doi:10.1007/s00508-017-1204-0. 